\title{
Characterization of chromosome fragmentation in two protozoans and identification of a candidate fragmentation sequence in Euplotes crassus
}

\author{
Scott E. Baird' and Lawrence A. Klobutcher ${ }^{2}$ \\ Department of Biochemistry, University of Connecticut Health Center, Farmington, Connecticut 06032 USA
}

Following the sexual cycle, hypotrichous ciliated protozoans fragment a set of their micronuclear chromosomes to generate the thousands of short, linear DNA molecules present in the transcriptionally active macronucleus. We have used a hybrid selection procedure to examine macronuclear DNA molecules for subtelomeric length heterogeneity to determine whether chromosome fragmentation occurs at unique or multiple sites. The results suggest that multiple, but closely spaced, chromosome fragmentation sites are used by Oxytricha nova. In contrast, Euplotes crassus uses unique chromosome fragmentation sites in a reproducible manner to generate the ends of macronuclear DNA molecules. Additional studies compared DNA sequences in the vicinity of chromosome fragmentation sites in an attempt to define cis-acting sequences that direct the fragmentation process. A conserved sequence was found near chromosome fragmentation sites in $E$. crassus. The location of the conserved sequence suggests that chromosome fragmentation involves staggered cuts of the micronuclear DNA molecules.

[Key Words: Chromosome fragmentation; DNA rearrangement; macronuclear development; Oxytricha nova; Euplotes crassus]

Received January 17, 1989; revised version accepted March 14, 1989.

The transcriptionally active macronuclear genome of unicellular hypotrichous ciliated protozoa, such as $\mathrm{Oxy}$ tricha nova and Euplotes crassus, consists of a highly amplified set of small, linear DNA molecules. For example, in O. nova there are $\sim 20,000$ different linear DNA molecules, with an average size of $2 \mathrm{kbp}$, each present in 1000 or more copies (Swanton et al. 1980). Each of these linear DNA molecules appears to contain a single coding unit (e.g., Helftenbein 1985), so that they are often called macronuclear genes. The macronuclear DNA molecules represent a portion of the genome of the second nucleus present in each cell, the micronucleus. The micronuclear genome has a chromosomal arrangement but is transcriptionally inert during vegetative growth of the organism. During each sexual phase of the life cycle, the macronucleus is destroyed and a new one is generated from a mitotic copy of the micronucleus via a complex series of genomic rearrangement events, including chromosome fragmentation and DNA elimination (for reviews, see Klobutcher and Prescott 1986;

${ }^{1}$ Current address: Department of Molecular Genetics, Albert Einstein College of Medicine, Bronx, New York 10461 USA.

${ }^{2}$ Corresponding author.
Steinbruck 1986). At the cytological level, the development of the new macronucleus begins with endoreplication of the micronuclear chromosomes, resulting in the formation of polytene chromosomes. The polytene chromosomes then are fragmented, and the resulting pieces are encased in vesicles. Once the vesicles form, the majority of the DNA in the developing macronucleus is degraded. Finally, the vesicle structures break down, and the remaining DNA undergoes several rounds of replication, resulting in the mature vegetative macronucleus. Comparisons of cloned segments of micronuclear and macronuclear DNA indicate that precursors of macronuclear DNA molecules reside at internal regions of the micronuclear chromosomes and generally are clustered in the genome (Klobutcher et al. 1986; Jahn et al. 1988a,b). Moreover, the micronuclear precursors lack the telomeric sequences characteristic of macronuclear DNA molecules (repeats of the octanucleotide $5^{\prime}-\mathrm{C}_{4} \mathrm{~A}_{4}$ $\left.-3^{\prime}\right)$, indicating that telomeres are added to macronuclear DNA molecules following their excision from the micronuclear genome (Oka and Honjo 1983; Dawson and Herrick 1984; Klobutcher et al. 1984).

Similar DNA rearrangement processes occur during macronuclear development in other ciliated protozoa, 
such as Tetrahymena and Paramecium but on a more limited level (for review, see Blackburn and Karrer 1986). For example, only a few hundred chromosome fragmentation events occur during macronuclear development in Tetrahymena, resulting in macronuclear DNA molecules with an average size of $\sim 600 \mathrm{kbp}$.

Chromosome fragmentation is one of the major events of macronuclear development in the ciliates and, as such, has been the subject of a number of studies. To a first approximation, chromosome fragmentation is a reproducible process. That is, at the level of resolution of agarose gel electrophoresis and Southern hybridization, all copies of most genes are contained on similarly sized macronuclear DNA molecules and the size does not vary through independent episodes of macronuclear development (Steinbruck 1983; Cartinhour and Herrick 1984; Roth and Prescott 1985). However, two types of observations indicate that variability in the use of chromosome fragmentation sites can occur. The first is alternative processing of the micronuclear DNA. Families of macronuclear DNA molecules have been noted in Oxytricha fallax (Cartinhour and Herrick 1984), O. nova (Klobutcher et al. 1988), and Paramecium (Forney and Blackburn 1988), whose members share a common core sequence, but have different lengths of DNA (differing by $>1 \mathrm{kbp}$ ) adjacent to the telomeric repeat sequences. In cases where the micronuclear organization of such macronuclear families has been examined, the results indicate that alternative use of chromosome fragmentation sites along the length of the micronuclear chromosome is responsible for generating such families (Herrick et al. 1987; Klobutcher et al. 1988). Second, evidence for an extended chromosome 'fragmentation domain,' as opposed to a unique fragmentation site, has been obtained based on terminal sequence analyses of multiple independent clones of particular macronuclear DNA molecules. In O. fallax, macronuclear DNA molecules have been found to differ by up to $33 \mathrm{bp}$ in their subtelomeric regions (Herrick et al. 1987), suggesting that multiple chromosome fragmentation sites exist within a defined region of the micronuclear chromosome. In Paramecium, the fragmentation domains appear to be much larger, as subtelomeric length heterogeneity of up to 800 bp has been observed (Baroin et al. 1987; Forney and Blackburn 1988).

It should be noted that models other than variable chromosome fragmentation can explain the observations discussed above. For instance, chromosome fragmentation may occur at single defined sites along the chromosome, but variable amounts of exonucleolytic digestion of the resulting ends prior to telomere addition could generate the observed terminal length heterogeneity of macronuclear DNA molecules. However, to simplify the discussion we will consider the entire series of events leading to the generation of a DNA end capable of receiving a telomere as 'chromosome fragmentation.'

In this study we examine macronuclear DNA molecules of O. nova and E. crassus for terminal length heterogeneity to determine whether chromosome fragmentation occurs at unique sites in these organisms. As an al- ternative to sequencing many independent clones of macronuclear DNA termini, a hybrid selection procedure was developed to isolate and size the termini of the many copies of a particular macronuclear DNA molecule in a cell line. Multiple, closely spaced, chromosome fragmentation sites appear to be used in the processing of the two ends of a macronuclear gene precursor in $O$. nova. In contrast, six macronuclear DNA termini in $E$. crassus were found to be invariant in size, implying that chromosome fragmentation occurs at unique sites in this organism. Additional studies compared the sequences of regions of the micronuclear chromosomes subject to fragmentation in an attempt to define cisacting DNA sequences that direct the chromosome fragmentation process in these two organisms. A conserved sequence element was identified near chromosome fragmentation sites in E. crassus, suggesting a model of the chromosome fragmentation event.

\section{Results and discussion}

Evidence for the use of multiple chromosome fragmentation sites by $\mathrm{O}$. nova

An initial indication that $O$. nova uses multiple chromosome fragmentation sites was obtained during the analysis of a $2.85-\mathrm{kb}$ macronuclear DNA molecule referred to as C3. As has been observed for a number of macronuclear DNA molecules in this species, two versions of $\mathrm{C} 3$, defined by restriction site differences (Fig. 1A), exist in the macronucleus. In a previous study, micronuclear and macronuclear recombinant clones of the two versions of C3 were isolated, and the chromosome fragmentation sites used to generate one of the macronuclear C3 DNA molecules defined by DNA sequence analysis (Klobutcher et al. 1986; Fig. 1A,B). To determine whether the second version of the $\mathrm{C} 3$ gene used the same chromosome fragmentation sites, selected regions of macronuclear clone LMAC3-G and micronuclear clone LMIC2-5 were sequenced (Fig. 1). The results indicate that the macronuclear $\mathrm{C} 3$ gene version represented by clone LMAC3-G is 8 bp longer at its left end and 3 bp shorter at its right end, compared with the version of $\mathrm{C} 3$ represented by clone pMAC3 (Fig. 1B).

The above results indicate that the micronuclear chromosomes containing the two different $\mathrm{C} 3$ gene precursors were fragmented at different sites during macronuclear development. One explanation of these results is that multiple chromosome fragmentation sites are used in this organism. The use of multiple fragmentation sites is formally possible within a clonal cell line because polytenization of the micronuclear chromosomes is an early event during macronuclear development, providing many DNA strands that can undergo fragmentation. Alternatively, chromosome fragmentation may be precise for each version, the difference in the observed positions arising from the small numbers of base changes that define the two versions (Fig. 1B).

To distinguish between these alternatives, we developed a variation on the hybrid selection procedure (Parnes et al. 1981) that allows the isolation and sizing of 
A.

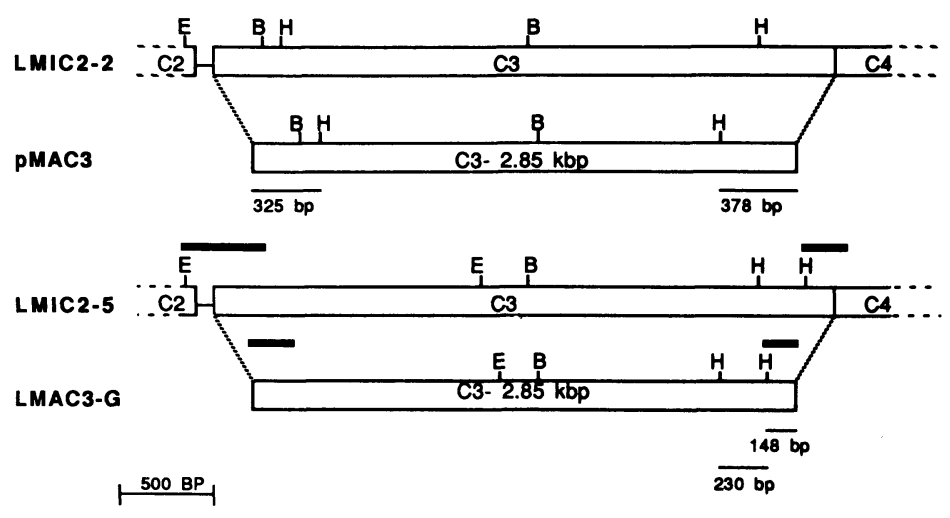

B.

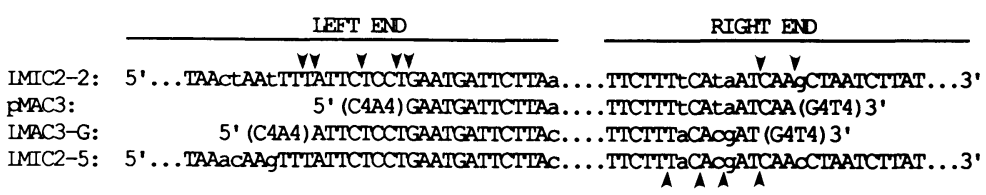

Figure 1. (A) Restriction maps of inserts in macronuclear clones pMAC3 and LMAC3-G, which represent the two versions of C3 macronuclear DNA molecules. Also shown are portions of the restriction maps of micronuclear clones LMIC2-2 and LMIC2-5, which contain the precursors of these two types of C3 macronuclear DNA molecules. Two additional precursors of macronuclear DNA molecules, $\mathrm{C} 2$ and $\mathrm{C} 4$, flank $\mathrm{C} 3$ in the micronucleus. The intergenic spacer that separates the $\mathrm{C} 2$ and $\mathrm{C} 3$ precursors in the micronuclear clone is indicated by a single line. Regions of clones LMIC2-5 and LMAC3-G that were sequenced to identify fragmentation sites are indicated by black boxes above the maps. The sizes of terminal restriction fragments isolated in hybrid selection experiments are indicated in base pairs. Note that slight differences in the restriction maps of micronuclear and macronuclear clones are due to the presence of internal eliminated sequences in the micronucleus (not shown) that are removed during development (Ribas-Aparicio et al. 1987). (E) EcoRI, (B) BamHI, and (H) HindIII. (B) DNA sequences of the left and right termini of the two macronuclear versions of $\mathrm{C} 3$ (clones pMAC3 and LMAC3-G) and the corresponding regions of their micronuclear precursors (clones LMIC2-2 and LMIC2-5). The left and right ends of the two C3 versions can be seen to differ by 8 and 3 $\mathrm{bp}$, respectively. Bases that differ between versions are shown in lowercase letters. Arrowheads denote fragmentation sites determined by hybrid selection analyses. terminal restriction fragments from the many copies of a particular macronuclear gene that exist in the amplified macronucleus (see Materials and methods). In brief, the procedure entails the immobilization of a recombinant clone containing the macronuclear gene to be analyzed on a small nitrocellulose filter. Total macronuclear DNA is treated so as to generate a small terminal restriction fragment radioactively labeled at one end for the macronuclear DNA molecule under analysis. The labeled total macronuclear DNA is then hybridized to the cloned DNA on the filter, and DNA fragments that have formed specific hybrids with the immobilized cloned DNA are eluted and analyzed on acrylamide sequencing gels using sequenced DNA as size markers. This procedure allows us to detect differences in terminal restriction fragment length of as little as $1 \mathrm{bp}$. In most experiments, the hybrid selection procedure was capable of detecting a subclass of terminal fragments if they composed at least $10 \%$ of the population.

To examine terminal length heterogeneity of the two versions of $\mathrm{C} 3$ by hybrid selection, HindIII-digested total macronuclear DNA was labeled by the Escherichia coli DNA polymerase I fill-in reaction (Maniatis et al. 1982) and hybridized to a nitrocellulose filter containing pMAC3 DNA. This strategy takes advantage of variable HindIII sites in the two versions of C3 (Fig. 1), so as to select distinctly sized terminal fragments from each end of each version. With the exception of the large left ter- minal HindIII fragment derived from the LMAC3-G-like versions of $\mathrm{C} 3$, the terminal fragments are sufficiently small so as to be precisely sized on DNA sequencing gels.

Hybrid-selected DNA fragments derived from the right end of LMAC3-G-like versions of C3 were first sized by examining DNA fragments in the 148-bp size range (Fig. 2A). A 148-bp fragment was observed, which was expected based on the sequence of clone LMAC3-G (Fig. 1A), along with fragments of 145, 143, and $140 \mathrm{bp}$. The additional three fragments represent successively shorter terminal fragments derived from other LMAC3G-like versions of $\mathrm{C} 3$. The intense band of $\sim 230 \mathrm{bp}$ (Fig. 2A) was found to be a doublet upon shorter autoradiographic exposure (data not shown) and corresponds to the two strands of the internal HindIII fragment of LMAC3-G-like versions of C3 (Fig. 1A). The fact that only two bands are observed in this region of the gel indicated that nonspecific exonucleolytic degradation is not occurring during the hybrid selection procedure and is not the explanation for the observed terminal fragment length heterogeneity.

In a similar manner, it was possible to assess terminal length heterogeneity of the two ends of pMAC3-like versions of C3 macronuclear DNA molecules. For the left ends, fragments of $325,326,329,333$, and $334 \mathrm{bp}$ were observed (Fig. 2B). A fragment of $325 \mathrm{bp}$ is predicted from the sequence of clone pMAC3. For the right end, 


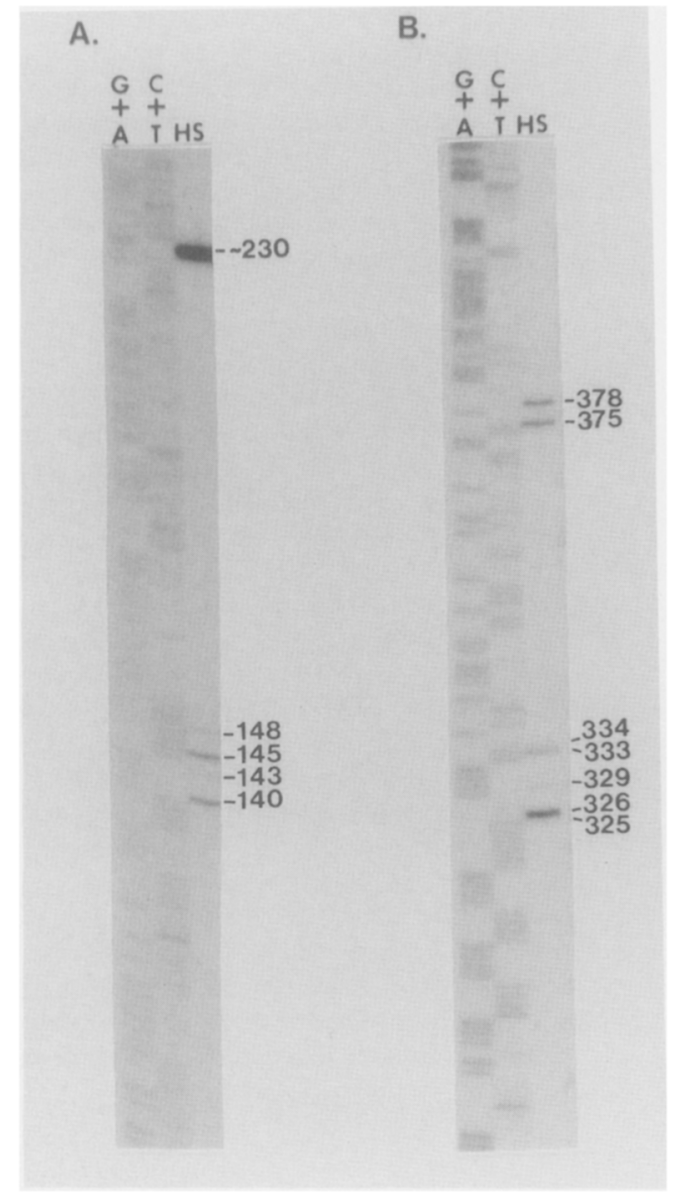

Figure 2. Autoradiographs of sequencing gels containing hybrid-selected DNA representative of the termini of O. nova C3 macronuclear DNA molecules. C3 terminal HindIII fragments from total macronuclear DNA digested with HindIII and 3'end-labeled, were hybrid selected using macronuclear clone pMAC3. (A) Hybrid-selected DNA fragments (lane HS) derived from the right termini of LMAC3-G-like copies of C3 are seen at $140,143,145$, and $148 \mathrm{bp}$. The band at $\sim 230$ bp represents an internal HindIII fragment. Sequence standards (lanes $G+A$ and $C+T$ ) are base-specific, chemical-cleavage reactions of a 2.1-kbp HindIII-SmaI fragment of clone LMAC3-G, which represents the region of LMAC3-G beginning at the right-most HindIII site of the insert (Fig. 1A) and extending through the right terminus into vector DNA, labeled at its $3^{\prime}$ end. $(B) \mathrm{Hy}$ brid-selected DNA fragments derived from the left and right termini of pMAC3-like versions of C3. Fragments seen in the 325-334-bp size range are derived from left ends of pMAC3like copies of $\mathrm{C} 3$, whereas the fragments at 375 and 378 bp represent two distinct right termini. Size standards (lanes $G+A$ and $C+T$ ) consist of a 0.5 -kbp HindIII-PvuII fragment of pMAC3, representing the left terminus of the insert, 3 '-end-labeled at the HindIII site and sequenced by the chemical cleavage method.

the expected fragment of $378 \mathrm{bp}$ was observed along with a $375 \mathrm{bp}$ fragment (Fig 2B).

These results indicate that terminal length heterogeneity exists for the three version-specific ends of macronuclear C3 genes examined. We suggest that this is the result of variability in the use of chromosome fragmentation sites. An alternative explanation might be that the teleomeric sequences can vary in length. We do not consider this a likely explanation of the results for the following two reasons: (1) Sequencing of $O$. nova total macronuclear DNA is consistent with a telomeric structure of invariant length (Klobutcher et al. 1981); (2) 19 cloned $O$. nova macronuclear termini have been sequenced (e.g., Klobutcher et al. 1981, 1986, 1988, and unpubl.; Boswell et al. 1982; Greslin et al. 1988; Harper and Jahn 1989|. All but three, which may be cloning artifacts, possessed the correct telomere length, implying that telomeres of abnormal length are infrequent. A second alternative explanation of our results, which we cannot rigorously exclude, is that subtelomeric heterogeneity resulted from deletion, insertion, or recombination events during vegetative growth of the organism.

Assuming that our hybrid selection results exclusively reflect use of variable chromosome fragmentation sites, the positions of the sites that would be used to generate the ends of the two C3 versions are indicated in Figure 1B. It is evident that some of the fragmentation sites are version specific, whereas others are used for both versions. The results obtained for the C3 gene are similar to those obtained for O. fallax and Paramecium, where all termini examined to date indicate the use of multiple fragmentation sites (Baroin et al. 1987; Herrick et al. 1987; Forney and Blackburn 1988). The primary difference of the C3 gene results is that the fragmentation sites are closely clustered, separated by a maximum of $9 \mathrm{bp}$. Fragmentation domains are somewhat larger in O. fallax, where DNA termini differing by 33 bp have been observed, and much larger in Paramecium, where fragmentation appears to occur over intervals hundreds of base pairs in length. Our results also extend these studies in that they indicate that fragmentation occurs only at a subset of the positions present within the fragmentation domain.

\section{E. crassus uses unique chromosome fragmentation sites in a reproducible manner}

More extensive studies on the fidelity of the chromosome fragmentation process were carried out on the hypotrichous ciliate E. crassus. Partially inbred strains of this organism have been generated that greatly reduce the version problem and simplify the analysis. In addition, it is possible to obtain viable offspring from this organism, so that the question of reproducibility could be addressed.

Five macronuclear DNA molecules, for which we have isolated and characterized macronuclear and micronuclear clones (S.E. Baird et al., in prep.), were examined using the hybrid selection procedure. The five macronuclear DNA molecules are referred to as V1, V2, V3, D7, and D8 and have sizes of 3.85, 0.94, 1.80, 1.65, and $1.55 \mathrm{kbp}$, respectively (Fig. 3). The precursors of D7 and D8 are adjacent in the micronuclear genome, separated by a 36-bp intergenic spacer. Similarly, the precursors of $\mathrm{V} 1, \mathrm{~V} 2$, and V3 are clustered in an independent region of 
A.

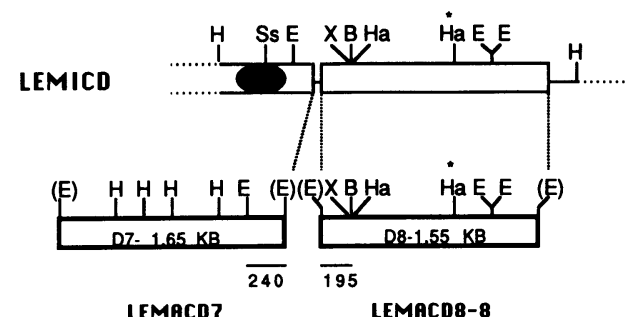

LEMACD7 LEMACD8-8 $1 \mathrm{~KB}$

B.

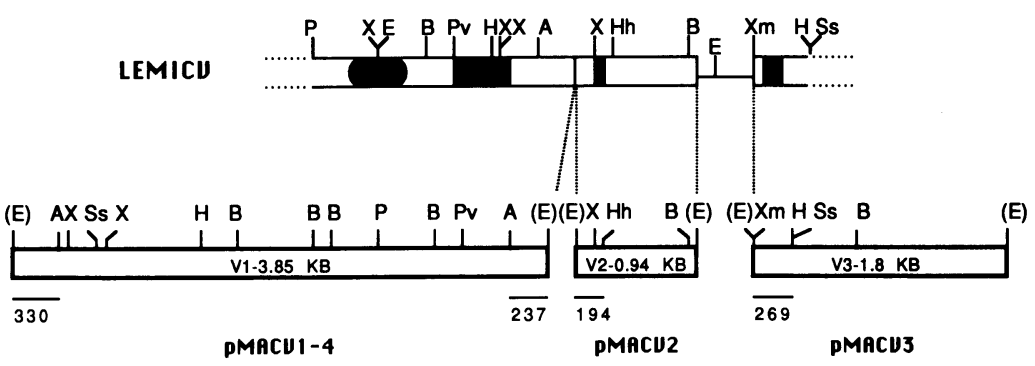

Figure 3. Restriction maps of recombinant clones of $E$. crassus macronuclear DNA molecules and their micronuclear precursors. $(A)$ Restriction maps of the inserts of clones LEMACD7 and LEMACD-8, which contain copies of the D7 and D8 macronuclear DNA molecules, respectively. Also shown is the region of clone LEMICD that contains the micronuclear precursors of these two macronuclear DNA molecules. In the micronuclear clone map, regions giving rise to macronuclear DNA molecules are shown as boxes, and spacers separating adjacent precursors as single lines. Internal eliminated sequences, which are removed from precursors during macronuclear development, are indicated by black ovals in cases where their precise position is unknown, and by black boxes in cases where they have been localized by sequence analysis. $\left(^{*}\right)$ The position of the variable HaeIII restriction site that defines the two forms of D8 macronuclear DNA molecules. Predicted sizes of terminal restriction fragments isolated in hybrid selection experiments are given below the maps in base pairs. (A) AluI, (B) BglII, (E) EcoRI, (H) HindIII, (Ha) HaeIII, (Hh) HhaI, (P) PstI, (Pv) PvuII, (Ss) SstI, (X) $X b a \mathrm{I}$, and $(\mathrm{Xm}) \mathrm{XmnI}$. Not all AluI, HaeIII, HhaI, PvuII, PstI, and XmnI sites are shown. Note that the EcoRI sites in parentheses at the ends of the macronuclear clone inserts result from the addition of linkers during the cloning process and are not present in the native macronuclear DNA molecules. $(B)$ Restriction maps of the inserts of clones pMACV1-4, pMACV2, and pMACV3, which contain copies of the V1, V2, and V3 macronuclear DNA molecules, respectively. Also shown is the restriction map of the region of micronuclear clone LEMICV that contains the precursors of the three macronuclear DNA molecules. Other aspects of the figure are as described above.

the micronuclear genome. The precursors of $\mathrm{V} 2$ and $\mathrm{V} 3$ are separated by a 400 -bp intergenic spacer, whereas the right end of V1 overlaps the left end of V2 by $6 \mathrm{bp}$. Genomic restriction mapping experiments indicate that only single versions of V1, V2, V3, and D7 exist in the macronucleus and micronucleus of $E$. crassus strain G1. Two forms or versions of D8 macronuclear DNA molecules exist in strain G1, which differ in the presence and absence of a HaeIII restriction endonuclease recognition site (Fig. 3A), but genetic studies have demonstrated that the two forms are allelic in this instance (Baird and Klobutcher 1988).

Prior to carrying out hybrid selection analyses, it was necessary to characterize the telomeric structure of $E$. crassus macronuclear DNA molecules. Based on sequencing the termini of cloned macronuclear DNA molecules, which were blunt-ended during the cloning process, the telomeres contain a 28-bp double-stranded region of $\mathrm{C}_{4} \mathrm{~A}_{4}$ repeats. The existence of a 14-bp $3^{\prime}$-single-stranded tail was deduced from sequencing total macronuclear DNA labeled at $3^{\prime}$ ends (data not shown), indicating the following telomeric structure:

\section{$5^{\prime}-\mathrm{C}_{4} \mathrm{~A}_{4} \mathrm{C}_{4} \mathrm{~A}_{4} \mathrm{C}_{4} \mathrm{~A}_{4} \mathrm{C}_{4} \mathrm{~N}_{17}$ ttgaa. $3^{\prime}-\mathrm{G}_{2} \mathrm{~T}_{4} \mathrm{G}_{4} \mathrm{~T}_{4} \mathrm{G}_{4} \mathrm{~T}_{4} \mathrm{G}_{4} \mathrm{~T}_{4} \mathrm{G}_{4} \mathrm{~T}_{4} \mathrm{G}_{4} \mathrm{~N}_{17}$ aactt.}

In the sequencing of total DNA, the sequence 5'TTGAA-3' was also readable above the general background at a position $17 \mathrm{bp}$ from the telomeric repeats (discussed further below). The deduced telomeric structure is identical to that obtained previously for the related hypotrich Euplotes aediculatus (Klobutcher et al. 1981).

The left end of the V3 gene was first examined for length heterogeneity by digesting $E$. crassus G1 wholecell DNA with HindIII and labeling the resulting fragments at their $3^{\prime}$ ends using the $E$. coli DNA polymerase I fill-in procedure. Labeled V3 gene fragments then were selected, using the macronuclear clone pMACV3. The left terminal HindIII fragment of V3 was predicted to be $269 \mathrm{bp}$ in length based on the sequence of clone pMACV3, and a single fragment of this size was observed in the hybrid selection analysis (Fig. 4A). The analysis was then repeated on E. crassus strain $\mathrm{NcCl0}$, and three cell lines generated from a mating of 


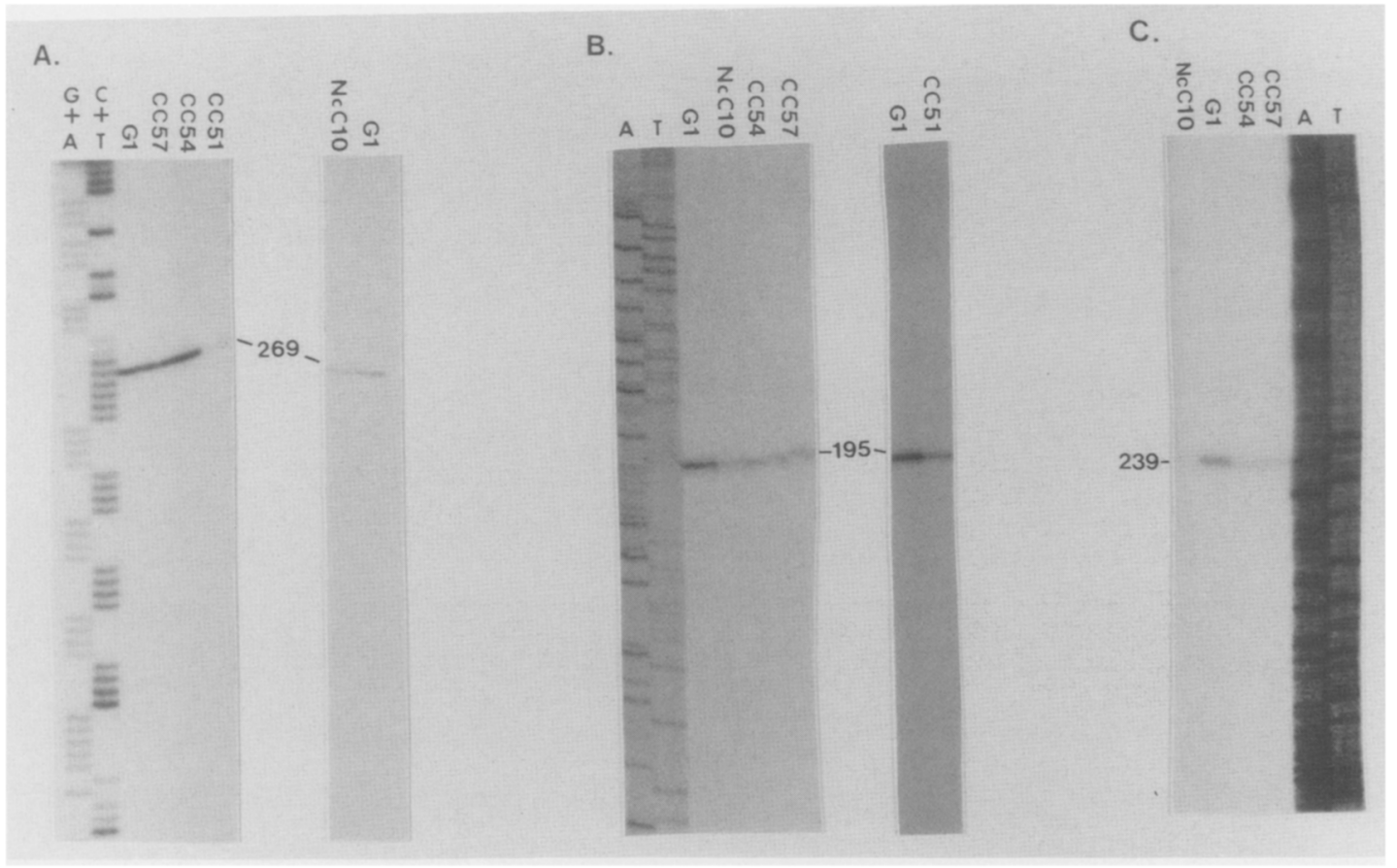

Figure 4. Autoradiographs from hybrid seletion experiments on the E. crassus V3, D8, and D7 macronuclear DNA molecules. $(A)$ Hybrid selection of left terminus-HindIII fragments of V3 from cell lines G1, NcC10, CC51, CC54, and CC57. In each case, terminal fragments were hybrid-selected from HindIII-digested total cellular DNA labeled at its 3' ends using clone pMACV3. Sizes of hybridselected fragments are indicated in base pairs. Size standards (lanes $G+A$ and $C+T$ ) consist of a $3^{\prime}$-end-labeled 0.28-kbp HindIII$B a m H I$ (vector site) fragment of clone pMACV3, which is essentially equivalent to the hybrid-selected fragments, sequenced by the chemical-cleavage method. $(B)$ Hybrid selection of the left terminus-BgIII fragments of D8 macronuclear DNA molecules. Terminal fragments were hybrid-selected from total cellular DNA, 3' end labeled at BglII sites, using a plasmid subclone containing the 1.15kbp EcoRI fragment of LEMACD8-8 (Fig. 3A). Size markers (lanes A,T) consist of the 0.20-kbp BglII-left terminus fragment of LMACD8-8 cloned in M13mpll and sequenced by the dideoxy chain-termination procedure. $(C)$ Hybrid selection of the right terminus-EcoRI fragments of D7 macronuclear DNA molecules. Terminal fragments were hybrid selected from total cellular DNA, 3' end labeled at EcoRI sites, using a plasmid subclone containing the 0.25-kbp EcoRI fragment of LEMACD7. Size standards (lanes A,T) consist of an M13mpll clone containing the $0.25-\mathrm{kbp}$ EcoRI fragment of LEMACD7 sequenced by the dideoxy chain-termination procedure.

G1 $\times$ NcC10, (lines CC51, CC54, and CC57). In each case, a single fragment of 269 bp was observed (Fig. 4A), indicating that a single fragmentation site is used to generate the left end of the macronuclear V3 gene and that this site is reproducibly used in subsequent rounds of macronuclear development.

Similar analyses were performed on the left end of D8 and the right end of D7. For D8, the left terminal BgIII fragment, which is predicted to be $195 \mathrm{bp}$ in length, was hybrid-selected from the same five cell lines used above. In each case, a single fragment of $195 \mathrm{bp}$ was detected (Fig. 4B). For D7, the right terminal EcoRI fragment with a predicted size of $240 \mathrm{bp}$ was hybrid-selected from G1, $\mathrm{NcC1} 10, \mathrm{CC} 54$, and CC57 total cellular DNA. Hybrid selection resulted in a single fragment with a size of 239 bp for each of the four cell lines (Fig. 4C), which is $1 \mathrm{bp}$ smaller than expected. This is likely to be the result of slight gel mobility differences between the hybrid-selected fragments and the size markers, which can occur as the result of differences in base composition (Landick et al. 1984). The markers used in this case were an M13 clone of the 240-bp right terminal EcoRI fragment of D8 sequenced by the dideoxy chain-termination method. Although the majority of the sequence standards should have the identical base composition of the hybrid-selected DNA, some M13 vector sequences are also contained on the standards that could affect mobility. Overall, however, the results indicate that single fragmentation sites are used to generate both the right end of D7 and the left end of D8.

Additional analyses were performed on the right end of V1 and the left end of V2. For each of these ends, an alternative labeling procedure was required in the hybrid selection procedure, as there were no convenient restriction sites that could be labeled by the $E$. coli DNA polymerase I fill-in procedure. To examine the right end of V1, total cellular DNA was first labeled at its $3^{\prime}$ ends by adding an $\alpha^{-32} \mathrm{P}$-labeled cordycepin residue, using the enzyme terminal deoxynucleotidyl transferase (Tu and Cohen 1980). The labeled DNA was then digested with AluI, generating an expected right terminal fragment of $237 \mathrm{bp}$ (including the cordycepin residue), and hybridized to a filter containing immobilized pMACVl-4 DNA. For cell lines NcC10, CC51, CC54, and CC57, a 
single band of 237 bp was observed as predicted (Fig. 5A; the second band observed on the gel is discussed below). For cell line G1, however, a band was seen at $236 \mathrm{bp}$, as well as $237 \mathrm{bp}$. We suspected that the shorter hybrid-selected fragments might have resulted from exonucleolytic 'nibbling' of the total cellular DNA prior to its use in the hybrid selection procedure. In contrast to the previous experiments, the labeling procedure employed here results in the detection of the DNA strand that contains the $5^{\prime}-\mathrm{G}_{4} \mathrm{~T}_{4}-3^{\prime}$ telomeric repeat sequence (referred to as the $3^{\prime}$ strand). The $3^{\prime}$ strand is extended 14 bp relative to the $5^{\prime}-\mathrm{C}_{4} \mathrm{~A}_{4}-3^{\prime}$ strand and is potentially more accessible to attack by single-stranded exonucleases. To determine whether nibbling was the cause of the above result, an alternative labeling procedure that removes the $3^{\prime}$ single-stranded tails of macronuclear
DNA molecules was employed (Herrick and Wesley 1978). Strain G1 total cellular DNA was first treated with T4 DNA polymerase in the presence of dATP, dTTP, and dCTP. Under these conditions, the $3^{\prime} \rightarrow 5^{\prime}$ exonuclease activity removes the single-stranded tail, as well as the first four $G$ residues of the double-stranded region of the telomere. The molecules were then labeled and blunt-ended by the addition of $\left[\alpha-{ }^{32}\right.$ P]dGTP to the reaction. Following AluI digestion and hybrid selection, a single fragment of $222 \mathrm{bp}$ was observed as expected, based on the labeling method (Fig. 5C). Thus, it appears that only a single fragmentation site is used to generate the right end of V1 in cell line G1, as well as the other cell lines examined.

In the analyses of V1 right ends, a second band of $\sim 330 \mathrm{bp}$ also was observed (Fig. 5A). Although the left

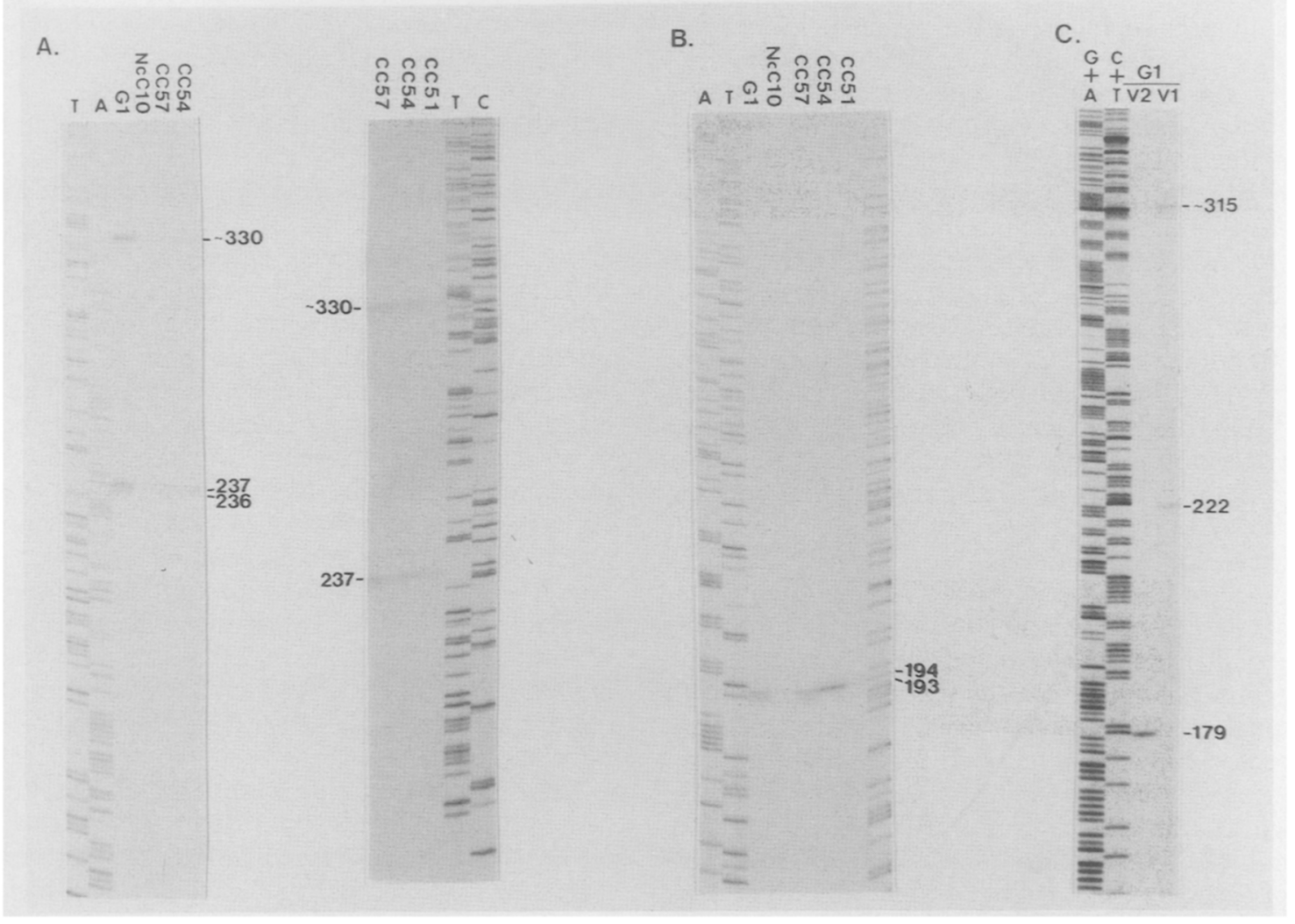

Figure 5. Autoradiographs of hybrid selection experiments of terminal fragments from V1 and V2 macronuclear DNA molecules of E. crassus cell lines G1, NcC10, CC51, CC54, and CC57. (A) Hybrid selection of the right terminus-AluI fragments of V1. Total cellular DNA was $3^{\prime}$-end-labeled with ${ }^{32} \mathrm{P}$-labeled cordycepin and digested with AluI, and hybrid selection was carried out using clone pMACV1-4. In addition to right terminal fragments of 236 and $237 \mathrm{bp}$, the band at $\sim 330 \mathrm{bp}$ represents left terminal fragments of V1. Size standards (lanes $A, T, C$ ) consist of an M13mpll clone contianing the 1.2-kbp EcoRI-PstI fragment of pMACV1-4 sequenced by the dideoxy chain-termination procedure. $(B)$ For hybrid selection of the left terminus HhaI-fragments of V2, total cellular DNA was 3 '-end-labeled with ${ }^{32}$ - -labeled cordycepin, digested with HhaI, and hybridized to a filter containing pMACV2 DNA. Size standards (lanes $A, T$ ) consist of an M13mp11 clone of the 800-bp EcoRI-BglII fragment of pMACV2 sequenced by the dideoxy chain-termination procedure. $(C)$ Hybrid selection of the V1 termini and the V2 left terminus from cell line G1 DNA blunt-ended and 3'-end-labeled using T4 DNA polymerase. Expected sizes of terminal fragments are $15 \mathrm{bp}$ smaller than in $A$ and $B$ due to removal of the 14 bp of single-stranded telomere and the lack of a cordycepin residue. Size standards (lanes $G+A$ and $C+T$ ) consist of an M13mp10 clone of a $0.28-\mathrm{kbp}$ HaeIII-EcoRI (left end) fragment of mMACV2 sequenced by the dideoxy chain-termination procedure. The size markers used in $A$ and $B$ were calibrated using the M13mp10 clone of the $0.28-\mathrm{kbp} H a e I I I-E c o R I$ fragment of pMACV2 (C). The latter clone produces standards that consist of the $\mathrm{G}_{4} \mathrm{~T}_{4}$-containing strand of $\mathrm{V} 2$, and are thus more closely related to the DNA strands isolated during hybrid selection. 
end of V1 has not been sequenced, a terminal AluI fragment of $\sim 350 \mathrm{bp}$ is expected on the basis of restriction mapping of clone pMACV1-4. The second band represents the left end of $\mathrm{V} 1$, and the results indicate that it is also generated by fragmentation at a unique site.

To examine the left end of V2, total cellular DNAs were 3 '-end-labeled using cordycepin and digested with HhaI to yield an expected fragment of $194 \mathrm{bp}$. Only fragments of 194 bp were observed in hybrid-selected DNA from cell lines $\mathrm{NcC10}$, CC54, and CC51 (Fig. 5B). Cell lines G1 and CC57 displayed the 194-bp fragment, as well as 193-bp fragments. The smaller fragments again appear to be the result of exonucleolytic nibbling during DNA isolation, as only a single band of the expected size was observed when G1 DNA was labeled by the T4 polymerase/blunt-ending procedure (Fig. 5C).

Overall, six ends of E. crassus macronuclear DNA molecules were examined in the above analyses and all were found to be generated by fragmentation at unique sites that are used reproducibly during independent episodes of macronuclear development. The results also indicate that the length of the telomeric repeats is invariant in this organism. The hybrid selection experiments on the left end of the D8 macronuclear DNA molecule were especially significant. As mentioned above, two allelic forms of D8 have been identified that differ in the presence or absence of a HaeIII restriction endonuclease recognition site. Cell lines G1, NcCl0, and CC54 are all heterozygous for the two forms of D8, whereas CC51 and CC57 are homozygous for the HaeIII minus and plus forms of D8, respectively (Baird and Klobutcher 1988). The isolation of single fragments of the expected size in the hybrid selection experiments indicates that both alleles use the same fragmentation site in a reproducible manner.

As we have no reason to expect that the macronuclear DNA molecules examined in the above experiments are in any sense unusual relative to other macronuclear DNA molecules, the results indicate that chromosome fragmentation at unique sites is a general property of this organism. E. crassus is the first ciliated protozoan to display such a characteristic, as all macronuclear chromosome ends examined in other species display terminal length variation that presumably results from the use of multiple fragmentation sites. This difference in fidelity of fragmentation extends to two other hypotrichous ciliated protozoa, O. nova and O. fallax, which both display macronuclear DNA molecules with heterogeneous ends (Herrick et al. 1987; see above).

\section{Fidelity of chromosome fragmentation and the resolution of overlapping macronuclear gene precursors}

The precursors of macronuclear DNA molecules have been found to be clustered and closely spaced in the micronuclear genome of hypotrichs (Boswell et al. 1983; Klobutcher et al. 1986; Jahn et al. 1988a,b). In fact, some macronuclear gene precursors appear to overlap by several base pairs. That is, several bases of the micronuclear chromosome ultimately are shared by two macronuclear
DNA molecules. In O. nova, the precursor of the C3 macronuclear DNA molecule appeared to overlap the precursor of a 5.0-kbp macronuclear DNA molecule (C4) by $5 \mathrm{bp}$ (Fig. 1A; Klobutcher et al. 1988). The conclusion in this case was not definitive, as the macronuclear $\mathrm{C} 4$ clone analyzed was of a different version than the macronuclear $\mathrm{C} 3$ and micronuclear clones. More recently we have found that the micronuclear precursors of V1 and V2 overlap by 6 bp in E. crassus (Fig 3; S.E. Baird et al., in prep.). In this instance, multiple versions are not a problem, as single forms of $\mathrm{V} 1$ and $\mathrm{V} 2$ exist in E. crassus strain G1.

Figure 6 presents three possible models for the resolution of macronuclear DNA molecules whose precursors overlap in the micronucleus. In the first model, the fragmentation event involves the generation of a staggered double-stranded cut of the DNA, much like some restriction endonucleases, generating ends with singlestranded tails. A DNA synthesis step to fill-in the ends prior to telomere addition would result in macronuclear DNA molecules that share the region defined by the staggered cut. The second and third models rely on the fact that chromosome fragmentation occurs after the formation of polytene chromosomes in the developing macronucleus, so that many DNA strands are available. In the second model, chromosome fragmentation occurs at either of two sites that define the region of overlap. Only those ends that receive the region of overlap can serve as substrates for telomere addition, giving rise to DNA molecules that reach the mature macronucleus. The molecules that lack the overlap are not substrates for telomere addition and are degraded at later stages of macronuclear development. The third model employs multiple chromosome fragmentation sites, with all of the resulting ends serving as substrates for telomere addition and reaching the mature macronucleus. In this last case, the appearance of overlapping precursors would result from analyzing macronuclear clones that were derived from different DNA strands during development; i.e., the two products derived from the fragmentation of a single strand of DNA would not share terminal sequences.

The hybrid selection experiments on the V1 and V2 genes allow us to rule out at least one of these models for $E$. crassus. Both V1 and V2 display no terminal heterogeneity, so that model three cannot be the mechanism by which these two macronuclear DNA molecules are generated. Both models I and II, however, give rise to macronuclear DNA molecules with discreet ends, so both remain possibilities for the resolution of overlapping precursors in this organism. The hybrid selection data are less informative for $O$. nova, where multiple fragmentation sites are observed. On the surface, model III is the most consistent with the results, as it relies on multiple fragmentation sites. However, if one incorporates the use of multiple fragmentation sites into both the first and second models, aspects of each might also be involved in the resolution of overlapping genes in $O$. nova. For instance, a modified model I with multiple staggered cuts that are all filled in prior to telomere addition is equally consistent with the data. 


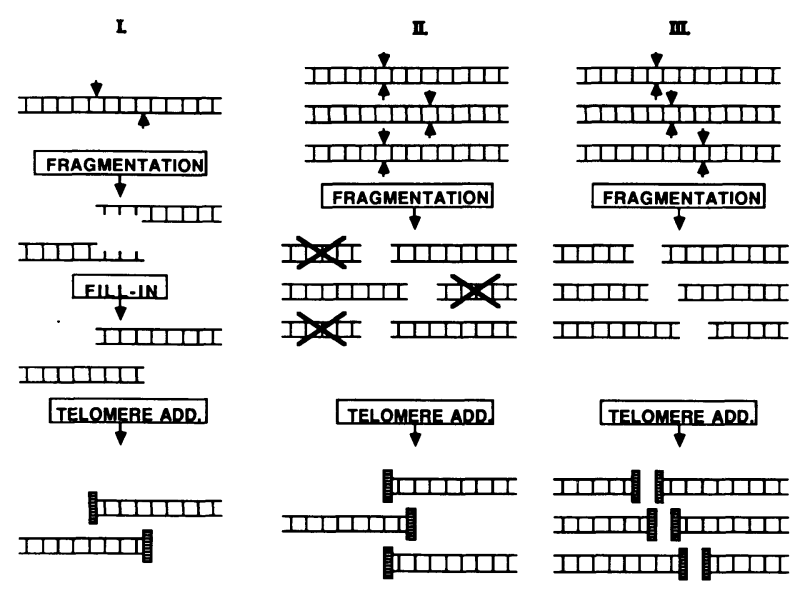

Figure 6. Three models for the resolution of overlapping macronuclear gene precursors from the micronuclear chromosome. DNA duplexes are shown with arrows indicating sites of cleavage for each strand. DNA molecules eliminated during macronuclear development are crossed out and telomeric repeats are indicated by hatched rectangles. The three models are described in the text.

\section{Identification of conserved DNA sequences in the vicinity of chromosome fragmentation sites}

The overall specificity of the chromosome fragmentation process implies that cis-acting DNA sequences exist that define the sites of chromosome fragmentation during macronuclear development. In an attempt to define such a putative fragmentation signal, we have compared previously determined sequences of regions of micronuclear DNA subject to fragmentation in O. nova and $E$. crassus. The analysis included cases where $100 \mathrm{bp}$ of sequence flanking both sides of the fragmentation site have been determined. This 200-bp interval is likely to contain any cis-acting fragmentation sequence for the following two reasons: (1) The intergenic spacers separating adjacent macronuclear gene precursors in the micronucleus are generally small and in only one instance exceed 100 bp (Klobutcher et al. 1986; 1988; S.E. Baird et al., in prep.); (2) coding sequences appear to occupy all but the terminal 100-200 bp of most macronuclear DNA molecules (e.g., Kaine and Spear 1982; Helftenbein 1985; see also Klobutcher and Prescott 1986).

Eight fragmentation sites have been sequenced in $O$. nova (Klobutcher et al. 1984, 1986, 1988; Ribas-Aparicio et al. 1987). We have been unable to detect any significant sequence features shared by all eight of these fragmentation sites. The $O$. nova fragmentation sequences also lacked significant similarity to the 15-bp chromosome breakage sequence (Cbs) that Yao et al. (1987) have found to be associated with chromosome fragmentation sites in the ciliate Tetrahymena. Overall, the situation for O. nova is similar to that reported for Paramecium (Baroin et al. 1987; Forney and Blackburn 1988) and $O$. fallax (Herrick et al. 1987), where no significant sequence features in the vicinity of fragmentation sites have been observed.

The sequences of six E. crassus chromosome fragmen- tation sites obtained from micronuclear clones LEMICD and LEMICV (S.E. Baird et al., in prep.) are shown in Figure 7A. To simplify Figure 7, only the $50 \mathrm{bp}$ preceding the chromosome fragmentation sites and the first $50 \mathrm{bp}$ of sequence that form the subtelomeric regions of the respective macronuclear DNA molecules are shown. Also shown are the subtelomeric sequences of the two ends of the 1.15-kbp E5 macronuclear DNA molecule. A potential candidate for a chromosome fragmentation signal was the conserved sequence $5^{\prime}$-TTGAA- $3^{\prime}$. As noted above, this short sequence was readable above background at a position $17 \mathrm{bp}$ from the end of the telomeric repeats when total, end-labeled macronuclear DNA was sequenced. An identical result was obtained previously for E. aediculatus (Klobutcher et al. 1981), and it was suggested that all ends of macronuclear DNA molecules possess this sequence $17 \mathrm{bp}$ from the terminal repeats. Inspection of the E. crassus sequences, however, indicates that only four (V2 left, D8 right, D7 right, and E5 left) of the nine macronuclear ends contain a perfect match of this sequence $17 \mathrm{bp}$ from the telomere addition site (Fig. 7A). For the three cases where the sequences of both ends of macronuclear DNA molecules were determined (V2, D8, and E5), the conserved sequence is found at only one end of each macronuclear DNA molecule.

The failure to find this conserved sequence at both ends of macronuclear DNA molecules suggests that it is not important for telomere structure per se. Instead, we believe that this pentanucleotide forms part of a larger consensus sequence that exists either within the macronuclear gene precursor or upstream of the fragmentation site in inverted orientation. The existence of such a larger consensus initially was indicated by significant similarities in the V1 left, D8 right, and V3 left fragmentation sequences just upstream of the chromosome fragmentation site (Fig. 7A). The core of these similar sequences consists of the sequence 5'-TTCAA-3', located $11 \mathrm{bp}$ upstream of the chromosome fragmentation site (5'-ATCAA-3' for V3 left). As this is the complement of the conserved sequence $17 \mathrm{bp}$ from the telomere addition site of macronuclear DNA molecules, we were prompted to reorient the fragmentation sequences based on the maximum homology to $5^{\prime}$-TTCAA-3' 11 bp prior to the fragmentation site, or $5^{\prime}-$ TTGAA-3' $^{\prime} 17 \mathrm{bp}$ past the fragmentation site. When this was done (Fig. 7B), it was possible to derive a consensus sequence of $5^{\prime}-\mathrm{A} / \mathrm{T} A / \mathrm{T}$ A/TTCAAY ${ }^{A} / \mathrm{TYYTAT}-3^{\prime}$ just upstream of the chromosome fragmentation sites (Fig. 7B).

This consensus sequence is moderately predictive of chromosome fragmentation sites. The $5080 \mathrm{bp}$ of $E$. crassus DNA that we have sequenced (S.E. Baird et al., in prep. and unpubl.) were searched with the consensus sequence, asking for sites that contained perfect matches of the six highly conserved residues (indicated above in boldface type) and an overall $85 \%$ identity to the extended consensus. Five of the seven fragmentation sites were picked up in the search, along with three other sites that are not subject to chromosome fragmentation. Thus, although the derived consensus sequence has some predictive value in identifying fragmentation sites, it is not a perfect indicator and suggests that other 
A.

V24 MACRONUCLEAR DNA MOLECULE

V1R/V2L. . AGTAACATTTGAAATCACAAAAGAATACTTATTTITCAAGATTTATATAA GTAAAATAATTATAATTAAATATGAGCGAAAGAGTTTATAAAAGAGGTAC.

\begin{tabular}{|c|c|c|}
\hline D8R & .. TCAATATGCATTTTATTTAATAATCAATAATATTTTCAATATTTATGAAA & GTTAAAATTATAAATACITGAAATTTTAATTTGCTTTAAGTAGG \\
\hline $3 L$ & . . ATTGGGGTTTTTAAGTTGTTAGAGAAATTAGGGAATCAATTTTTTTGGGA & GAAAATATTCAAATTTTAAAAACATTATTTTTAAAAATGGACAGGACTAA. . \\
\hline $2 R$ & . TTACTTGAGGGGTTGGGGGTAGAGGTGAGGGGAGGTTGGGAATTTAGGGG & GATTTAAGTGGTGGGGGTTGGTTAGATTATAAATGGTGATTGTATTAGA? \\
\hline R & AAATTGGAGAAATACTATAAGCC & TTCGTTTTGTATTTGAGTTGAAAAATGAACTAGTTAATATATTTAATAAR \\
\hline $3 \mathrm{~L}$ & .. AAATACAAAACGAATGTAGGTATTCCATTATGGCTTATAGTATTTCTCCA & TTAGAGTACAGTAGCTGAATTAATAATTATTCCTGAATTTI \\
\hline & & AATACTTGTTAAAATTTGAAATAAAATTATAAATTTT \\
\hline & & TGAACCTTGATTATGGATTAAGAATTTTAGAA \\
\hline
\end{tabular}

B.

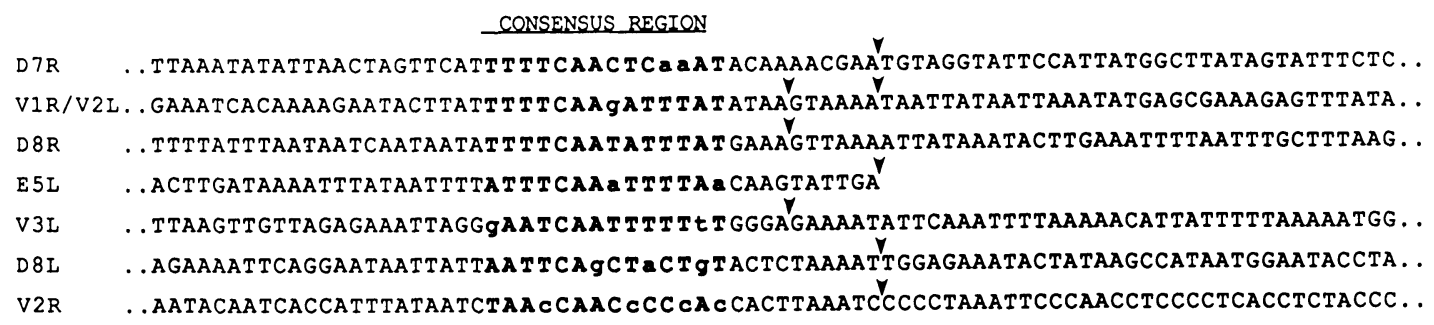

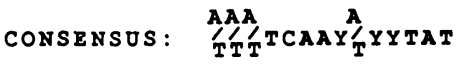

$\overline{\text { C. }}$

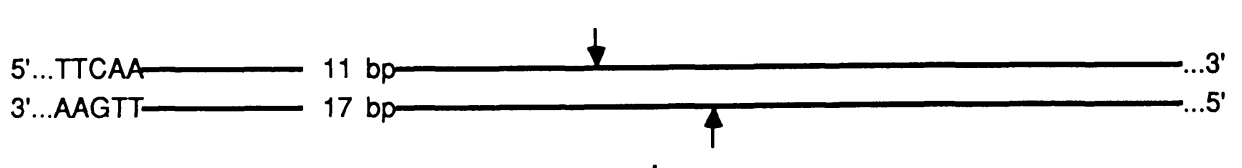

$\downarrow$ FRAGMENTATION AND FILL-IN

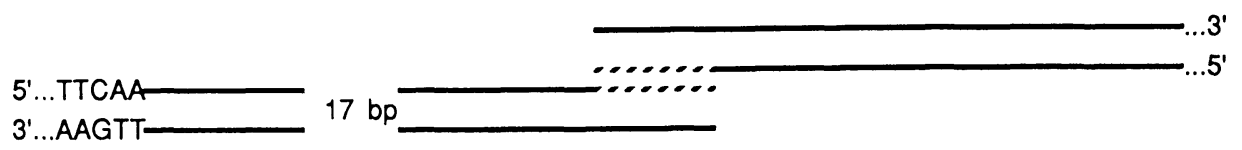

TELOMERE ADDITION?

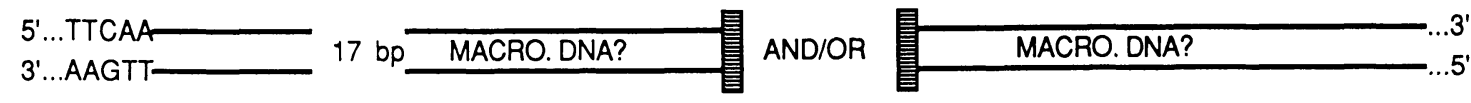

Figure 7. (A) Sequences in the vicinity of six fragmentation sites in E. crassus, as well as the subtelomeric sequences of the E5 macronuclear DNA molecule. For the six fragmentation sites, the 50 bp preceding the fragmentation site is shown, followed by the first $50 \mathrm{bp}$ of sequence that ultimately form the subtelomeric region of the macronuclear DNA molecule. The gap in the sequence denotes the fragmentation site. $(\mathrm{L}, \mathrm{R})$ Denote the left and right ends, respectively, of macronuclear gene precursors. All sequences are shown reading $5^{\prime} \rightarrow 3^{\prime}$. The sequence $5^{\prime}$-TTGAA-3' is underlined in cases where it is located within a macronuclear gene precursor 17 bp from the telomere addition site. $\left(^{*}\right)$ Identical nucleotides preceding the fragmention site for V1R/V2R versus D8R and D8R versus V3L. The V1R/V2L sequence represents overlapping precursors and is shown reading toward the right end of V1. The position of the fragmentation site generating the left end of $\mathrm{V} 2$ is indicated along with the direction of the $\mathrm{C} 2$ macronuclear DNA molecule (arrow). $(B)$ Realignment of the $E$. crassus fragmentation sequences illustrates a consensus sequence $[(\mathrm{R})$ purine; $(\mathrm{Y})$ pyrimidine $]$ in the vicinity of fragmentation sites. The V1R/V2L, D8R, and V3L sequences are oriented as in $A$, whereas the reverse complements of the D7R, E5L, D8L, and V2R sequences are shown. For each fragmentation sequence, the consensus region is indicated in boldface type, with mismatches to the overall consensus sequence indicated in lowercase letters. Arrows denote the positions of chromosome fragmentation. $(C)$ A model for the chromosome fragmentation event. The 5'-TTCAA-3' sequence corresponds to the generally conserved nucleotides in the consensus sequence. Fragmentation occurs 11 bp downstream of this sequence on one DNA strand but 17 bp downstream on the opposite strand, generating termini with 6-bp 5' overhangs. One or both of the resulting termini can serve as a substrate for telomere addition ultimately resulting in a macronuclear DNA molecule(s).

sequence features in the vicinity may also be important in defining fragmentation sites.

The fragmentation site that showed the least similarity to the derived consensus was the one near the right end of V2 (Fig. 7B). This fragmentation site is also unusual in possessing a high degree of $\mathrm{G} / \mathrm{C}$ strand asymmetry. In the $100 \mathrm{bp}$ of the V2 right fragmentation sequence shown in Figure $7 \mathrm{~A}$, there are $44 \mathrm{G}$ residues and 
only a single $\mathrm{C}$ residue. Moreover, the $\mathrm{G} / \mathrm{C}$ asymmetry actually extends to the entire 400-bp intergenic spacer that separates the right end of V2 from the left end of V3 in the macronucleus. Beginning at the left end of V2 and containing toward V3, the first $167 \mathrm{bp}$ of the intergenic spacer contain $82 \mathrm{C}$ residues and only $8 \mathrm{G}$ residues, whereas the last $233 \mathrm{bp}$ contain $93 \mathrm{G}$ residues and $7 \mathrm{C}$ residues (S.E. Baird et al., in prep.). A similar strand asymmetry has been observed in the terminal inverted repeats of a transposon-like element in the micronuclear genome of O. fallax (Herrick et al. 1985), and two of the $O$. nova fragmentation sequences display G/C strand asymmetry either upstream or downstream of the chromosome fragmentation site (see $\mathrm{C} 2$ left and $\mathrm{C} 3$ right/C4 left in Klobutcher et al. 1984 and 1988, respectively). The significance of these unusal regions is unknown, but they may be involved in defining a second class of fragmentation sites.

The position of the consensus sequence suggests a model of the chromosome fragmentation event (Fig. 7C). When the consensus is located in sequences destined to form part of the macronuclear DNA molecule (e.g., E5 left), telomeres are added at a position $17 \mathrm{bp}$ from the highly conserved $5{ }^{\prime}-\mathrm{A} / \mathrm{T}$ TCAA- $3^{\prime}$ of the consensus sequence. When the consensus sequence resides outside the macronuclear gene precursor (e.g., D8 right), the subtelomeric region of the macronuclear DNA molecule begins $11 \mathrm{bp}$ from the highly conserved pentanucleotide. This dual arrangement of the consensus sequence could be accommodated if the initial fragmentation event results in a staggered cut in the DNA generating a 6-bp 5' overhang, which is subsequently filled-in prior to telomere addition (Fig. 7C). Whether the DNA molecules to the left and/or right of the fragmentation site ultimately appear in the mature macronucleus could be controlled by other factors. For instance, some of the DNA ends may not be recognized as substrates for telomere addition and, hence degraded later in development, or some of the resulting DNA molecules may lack origins of DNA replication. The staggered-cut model is particularly attractive because it is consistent with the resolution of V1 and V2, which overlap by $6 \mathrm{bp}$ in the micronucleus. In this case, the consensus sequence resides in the V2 precursor (Fig. 7B) but would be sufficient to generate the ends of two macronuclear DNA molecules. It will be of interest to determine whether other overlapping macronuclear gene precursors in E. crassus overlap by 6 bp as predicted by this model.

Although the above model postulates a $5^{\prime}$ overhang, the data are consistent with the fragmentation event generating molecules with a 6-bp $3^{\prime}$ overhang. In this case, telomeric repeats might be added directly to the $3^{\prime}$ overhang, and the $5^{\prime}$ gap filled-in later. Such a scenario is attractive because the telomere terminal transferase activities that have been detected in protozoa are capable of adding telomeric repeats to the $3^{\prime}$ ends of oligonucleotides that correspond to the natural $3^{\prime}$ ends of telomeres (Greider and Blackburn 1985; Zahler and Prescott 1988; Shippen-Lentz and Blackburn 1989|. Although not yet demonstrated, it is possible that this activity also recognizes DNA molecules with a specific terminal structure and is responsible for the de novo telomere addition that occurs during macronuclear development.

The ability to detect the consensus sequence was aided greatly by its defined positions relative to the unique chromosome fragmentation sites used by $E$. crassus. It may be that similar weak consensus sequences exist in organisms such as Paramecium and Oxytricha, but have been difficult to detect because of the use of multiple chromosome fragmentation sites in these organisms (Baroin et al. 1987; Herrick et al. 1987; Forney and Blackburn 1988). In comparison to the Tetrahymena Cbs element, the conserved E. crassus sequence displays two significant differences. First, the 15-bp Cbs element is strictly conserved at all Tetrahymena chromosome fragmentation sites (Yao et al. 1987), whereas the E. crassus consensus sequence is comparatively loose and appears to tolerate a number of base mismatches. This may be related to the greater number of fragmentation events in E. crassus. Second, the Tetrahymena Cbs element always resides within the DNA eliminated during macronuclear development and not within the macronuclear DNA molecule that results from the fragmentation event (Yao et al. 1987).

Whether or not the consensus sequence defined for $E$. crassus actually specifies the position of chromosome fragmentation will clearly require further studies. The possibility of adapting procedures that have been used successfully for DNA transformation of Tetrahymena (Tondravi and Yao 1986) to hypotrichous ciliates, in conjunction with in vitro mutagenesis of fragmentation sites, may make it possible to address directly the involvement of our putative chromosome fragmentation signal. Alternatively, the ability to prepare large numbers of $E$. crassus cells synchronously proceeding through macronuclear development (Roth et al. 1985) may allow the development of an in vitro chromosome fragmentation system to test the involvement of the fragmentation consensus sequence.

\section{Materials and methods}

\section{E. crassus cell lines and DNA isolation}

The E. crassus cell lines used in these studies were derived from cells originally isolated by Dr. P. Luporini (University of Camerino, Italy), from San Terenzio, Italy. Strain Gl is a partially inbred mating type I cell line $\left(\mathrm{mt}^{1} / \mathrm{mt}^{1}\right.$; for a discussion of the mating type system, see Heckmann 1964). Other cell lines used were NcC10, a mating type III cell line $\left(\mathrm{mt}^{3} / \mathrm{mt}^{1}\right)$, and cell lines CC51, CC54, and CC57, which were derived from a mating of $\mathrm{Gl}$ and $\mathrm{NcCl} 10$ as described previously (Baird and Klobutcher 1988). E. crassus cell lines were grown and maintained in supplemented artificial seawater (Instant Ocean, Aquarium Systems; Mentor, Ohio), using the marine algae Dunaliella salina as a food source, as described by Roth et al. (1985).

O. nova strain H10, a clonal cell line, was grown using the algae Chlorogonium as a food source (Swanton et al. 1980).

\section{DNA isolation}

Total cellular DNA and macronuclear DNA were isolated from the hypotrichous ciliated protozoa using established methods 
(Lauth et al. 1976; Klobutcher et al. 1981, 1984). Bacterial plasmid DNAs were prepared using either the SDS-lysis or the alkaline-lysis procedures (Godson and Vapnek 1973; Maniatis et al. 1982). Recombinant bacteriophage were purified on glycerol step gradients, and DNA was prepared as described by Maniatis et al. (1982).

\section{Restriction endonuclease digestions and agarose gel electrophoresis}

DNAs were digested with restriction enzymes in accordance with the manufacturers' directions (New England Biolabs, Inc., Beverly, Massachusetts; Bethesda Research Laboratories, Bethesda, Maryland). DNAs were sized by electrophoresis through agarose or low-melting-point agarose gels prepared and run in TBE buffer [ $89 \mathrm{~mm}$ Tris base, $89 \mathrm{~mm}$ boric acid, $2 \mathrm{~mm}$ EDTA (pH 8.0)].

\section{DNA sequence analysis}

DNA fragments were cloned into bacteriophage M13 mp8, $\mathrm{mp} 9, \mathrm{mpl0}$, or mpll and sequenced by the dideoxy chain-termination method (Sanger et al. 1977) using kits purchased from New England Biolabs or United States Biochemical Corp. (Cleveland, Ohio) and $\alpha$-thio- ${ }^{35}$ S-labeled dATP as the labeled nucleotide triphosphate. Alternatively, the chemical cleavage sequencing method was employed using DNA fragments labeled at a 3' end (Maxam and Gilbert 1980).

The terminal sequences of the 1.15-kbp E5 macronuclear DNA molecule were determined from clone EMAC5. 3 '-end-labeled terminal fragments of the EMAC5 insert were generated and sequenced by the chemical cleavage method.

DNA sequences were analyzed using an IBM PC equipped with IBI/Pustell Sequence Analysis software (International Biotechnologies, New Haven, Connecticut). Alternatively, a Homo sapiens data processor, equipped with a complex optical scanner, was employed.

\section{DNA labeling}

Macronuclear DNA or total cellular DNA used in hybrid selection was radioactively labeled by several procedures. In most cases, $10 \mu \mathrm{g}$ of DNA was first digested with a restriction enzyme that generates recessed 3 '-ends and then labeled by filling in the resulting gaps using $E$. coli DNA polymerase I, along with one $\alpha^{-32} \mathrm{P}$-dNTP and other unlabeled dNTPs (Maniatis et al. 1982). Alternatively, the natural $3^{\prime}$ termini of macronuclear DNA molecules were radiolabeled by the addition of an $\alpha^{-32}$ P. labeled cordycepin (New England Nuclear, Boston, Massachussetts) residue, using the enzyme terminal deoxynucleotidyl transferase (Tu and Cohen 1980). In some cases, the DNA was labeled via minor modifications of a procedure originally described by Herrick and Wesley (1978), which removes the 3' single-stranded tail of the telomeres of native macronuclear DNA molecules and introduces $\alpha^{-32}$ P-labeled nucleotides at the 3 ' end of the double-stranded region of the telomeres. For this procedure, $10-15 \mu \mathrm{g}$ of DNA was added to a reaction mixture consisting of $2.5 \mathrm{~mm}$ dTTP, $2.5 \mathrm{mM}$ dATP, $16.6 \mathrm{mM} \mathrm{NH}_{4} \mathrm{SO}_{4}$, $67 \mathrm{~mm}$ Tris- $\mathrm{Cl}$ ( $\mathrm{pH} 8.0$ ), $6.7 \mathrm{mM} \mathrm{MgCl}_{2}$, and $10 \mathrm{~mm} \beta$-mercaptoethanol. Ten units of bacteriophage T4 DNA polymerase were added and the mixture incubated at $37^{\circ} \mathrm{C}$ for $15 \mathrm{~min}$. Then, $200 \mu \mathrm{Ci}$ of $\alpha^{-32} \mathrm{P}$-labeled dGTP were added to the reaction mixture, and incubation continued for $15 \mathrm{~min}$ more. As a final step, the reaction mixture was made $250 \mathrm{mM}$ dGTP and incubated for an additional $5 \mathrm{~min}$ to ensure that blunt-ended telomeres were formed. The labeled DNA was ethanol-precipitated prior to use in the hybrid selection protocol.

\section{Hybrid selection}

Hybrid selection was carried out using $1-\mathrm{cm}^{2}$ nitrocellulose filters containing $5 \mu \mathrm{g}$ of a recombinant plasmid clone harboring a copy of the target macronuclear DNA molecules. The filters were prepared by first soaking them in $6 \times$ SSC $[1 \times$ SSC $=0.15 \mathrm{M} \mathrm{NaCl}, 0.015 \mathrm{M} \mathrm{Na}$-citrate $(\mathrm{pH} 7.0)]$ and then blotting them to remove excess moisture. Plasmid DNA was brought to a volume of $50 \mu \mathrm{l}$ in distilled water, denatured by heating at $100^{\circ} \mathrm{C}$, and immediately applied to the filters. The filters were allowed to air-dry, baked at $80^{\circ} \mathrm{C}$ for $2 \mathrm{hr}$ under vacuum, and stored at room temperature until use.

Prehybridization and hybridization of the filters were carried out essentially as described previously (Boswell et al. 1982), except that the hybridizations were performed at $65^{\circ} \mathrm{C}$ in $1.5-\mathrm{ml}$ microcentrifuge tubes using $1 \mathrm{ml}$ of hybridization solution. Following hybridization for 20-24 hr with labeled genomic DNA, the filters were removed from the microcentrifuge tubes and washed twice for $30 \mathrm{~min}$ at $65^{\circ} \mathrm{C}$ in $50 \mathrm{ml}$ of $2 \times \mathrm{SSC}, 0.5 \%$ SDS, followed by two additional washes in $0.1 \times$ SSC $0.5 \%$ SDS. In cases where the hybrid-selected DNA fragments were expected to be $<150 \mathrm{bp}$, the second pair of washes was done in $0.2 \times$ SSC, $0.5 \%$ SDS. Following the washes, the filter was rinsed in $0.1 \times$ SSC at room temperature transferred to a microcentrifuge tube containing $150 \mu$ l of TE $[10 \mathrm{mM}$ Tris- $\mathrm{HCl}, 0.1$ mM EDTA, (pH 8.0)], and boiled for $3 \mathrm{~min}$ to elute the specifically bound, hybrid-selected DNA fragments. The TE was removed and saved, and the boiling step repeated using $150 \mu \mathrm{l}$ of fresh TE solution. The TE solutions were then pooled, and hybrid-selected DNAs recovered by ethanol precipitation using 5 $\mu \mathrm{g}$ of $E$. coli tRNA as carrier. The hybrid-selected DNAs were resuspended in 5-10 $\mu$ l of loading buffer and analyzed by electrophoresis on $6 \%$ or $8 \%$ acrylamide-urea DNA sequencing gels (Maxam and Gilbert 1980), using sequenced DNAs as size standards.

\section{Acknowledgments}

We would like to thank Dr. Ann Cowan and Ms. S.L. Tausta for their critical reading of the manuscript. The work was supported by U.S. Public Health Service grant GM-33277 and a grant from the University of Connecticut Research Foundation.

\section{References}

Baird, S.E. and L.A. Klobutcher. 1988. Genetic characterization and use of a restriction fragment length variant in the hypotrichous ciliate Euplotes crassus. J. Protozool. 35: 459-465.

Baroin, A., A. Prat, and F. Caron. 1987. Telomeric site position heterogeneity in macronuclear DNA of Paramecium primaurelia. Nucleic Acids Res. 15: 1717-1728.

Blackburn, E.H. and K. Karrer. 1986. Genomic reorganization in ciliated protozoans. Annu. Rev. Genet. 20: 501-521.

Boswell, R.E., L.A. Klobutcher, and D.M. Prescott. 1982. Inverted terminal repeats are added to genes during macronuclear development in Oxytricha nova. Proc. Natl. Acad. Sci. 79: 3255-3259.

Boswell, R.E., C.L. Jahn, A.F. Greslin, and D.M. Prescott. 1983. Organization of gene and non-gene sequences in micronuclear DNA of Oxytricha nova. Nucleic Acids Res. 11: 3651-3663.

Cartinhour, S.W. and G.A. Herrick. 1984. Three different macronuclear DNA molecules in Oxytricha fallax share a common sequence block. Mol. Cell. Biol. 4: 931-938.

Dawson, D. and G. Herrick. 1984. Rare internal $\mathrm{C}_{4} \mathrm{~A}_{4}$ repeats in the micronuclear genome of Oxytricha fallax. Mol. Cell. Biol. 4: 2661-2667. 
Forney, J.D. and E.H. Blackburn. 1988. Developmentally controlled telomere addition in wild-type and mutant Paramecia. Mol. Cell. Biol. 8: 251-258.

Godson, G.N. and D. Vapnek. 1973. A simple method of preparing large amounts of $\phi X 174$ RFI supercoiled DNA. Biochim. Biophys. Acta 299: 516-520.

Greider, C.W. and E.H. Blackburn. 1985. Identification of a specific telomere transferase activity in Tetrahymena extracts. Cell 43: 405-413.

Greslin, A.F., S.H. Loukin, Y. Oka, and D.M. Prescott. 1988. An analysis of the macronuclear actin genes of Oxytricha. DNA 7: $529-536$

Harper, D.S. and C.L. Jahn. 1989. Actin, tubulin, and H4 histone genes in three species of hypotrichous ciliated protozoa. Gene 75: 93-107.

Heckmann, K. 1964. Experimentelle untersuchungen an Euplotes crassus I. Paarungssystem, konjugation, und determination der paarungstypen. Z. Vereburngsl. 95: 114-124.

Helftenbein, E. 1985. Nucleotide sequence of a macronuclear DNA molecule coding for $\alpha$-tubulin from the ciliate Stylonychia lemnae. Nucleic Acids Res. 13: 415-433.

Herrick, G. and R.D. Wesley. 1978. Isolation and characterization of a highly repetitious inverted terminal repeat sequence from Oxytricha macronuclear DNA. Proc. Natl. Acad. Sci. 75: 2626-2630.

Herrick, G., D. Hunter, K. Williams, and K. Kotter. 1987. Alternative processing during development of a macronuclear chromosome family in Oxytricha fallax. Genes Dev. 1: 1047-1058.

Herrick, G., S. Cartinhour, D. Dawson, D. Ang, R. Sheets, A. Lee, and K. Williams. 1985. Mobile elements bounded by $\mathrm{C}_{4} \mathrm{~A}_{4}$ telomeric repeats in Oxytricha fallax. Cell 43: 759768.

Jahn, C.L., L.A. Nilles, and M.F. Frikau. 1988a. Organization of the Euplotes crassus micronuclear genome. J. Protozool. 35: $590-601$.

Jahn, C.L., K.E. Prescott, and M.W. Waggener. 1988b. Organization of the micronuclear genome of Oxytricha nova. Genetics 120: 123-134.

Kaine, B.P. and B.B. Spear. 1982. Nucleotide sequence of a macronuclear gene for actin in Oxytricha fallax. Nature 295: 430-432.

Klobutcher, L.A. and D.M. Prescott. 1986. The special case of the hypotrichs. The molecular biology of ciliated protozoa. (ed J. Gall), pp. 111-154. Academic Press, New York.

Klobutcher, L.A., M.E. Huff, and G.E. Gonye. 1988. Alternative use of chromosome fragmentation sites in the ciliated protozoan Oxytricha nova. Nucleic Acids Res. 16: 251-264.

Klobutcher, L.A., C.L. Jahn, and D.M. Prescott. 1984. Internal sequences are eliminated from genes during macronuclear development in the ciliated protozoan Oxytricha nova. Cell 36: 1045-1055.

Klobutcher, L.A., M.S. Swanton, P. Donini, and D.M. Prescott. 1981. All gene-sized DNA molecules in four species of hypotrichs have the same terminal sequence and an unusual 3' terminus. Proc. Natl. Acad. Sci. 78: 3015-3019.

Klobutcher, L.A., A.M. Vailonis-Walsh, K. Cahill, and R.M. Ribas-Aparicio. 1986. Gene-sized macronuclear DNA molecules are clustered in micronuclear chromosomes of the ciliate Oxytricha nova. Mol. Cell. Biol. 6: 3606-3613.

Landick, R., D. Maguire, and L.C. Lutter. 1984. Optimization of polyacrylamide gel electrophoresis conditions used for sequencing mixed oligodeoxyribonucleotides. DNA 3:413419.

Lauth, M.R., B.B. Spear, J. Heumann, and D.M. Prescott. 1976. DNA of ciliated protozoa: DNA seqeunce diminution during macronuclear development of Oxytricha. Cell 7: $67-74$

Maniatis, T., E.F. Fritsch, and J. Sambrook. 1982. Molecular cloning: A laboratory manual. Cold Spring Harbor Laboratory, Cold Spring Harbor, New York.

Maxam, A.M. and W. Gilbert. 1980. Sequencing end-labeled DNA with base-specific chemical cleavages. Methods Enzymol. 65: 499-560.

Oka, Y. And T. Honjo. 1983. Common terminal repeats of the macronuclear DNA are absent from the micronuclear DNA in hypotrichous ciliate Stylonychia pustulata. Nucleic Acids Res. 11: 4325-4333.

Parnes, J.R., B. Velan, A. Felsenfeld, L. Ramanathan, U. Ferrini, E. Appella, and J.G. Seidman. 1981. Mouse $B_{2}$ microglobulin cDNA clones: A screening procedure for cDNA clones corresponding to rare mRNAs. Proc. Natl. Acad. Sci. 78: 22532257.

Ribas-Aparicio, R.M., J.J. Sparkowski, A.E. Proulx, J.D. Mitchell, and L.A. Klobutcher. 1987. Nucleic acid splicing events occur frequently during macronuclear development in the protozoan Oxytricha nova and involve the elimination of unique DNA. Genes Dev. 1: 323-336.

Roth, M.R. And D.M. Prescott. 1985. DNA intermediates and telomere addition during genome reorganization in Euplotes crassus. Cell 41: 411-417.

Roth, M., M. Lin, and D.M. Drescott. 1985. Large scale synchronous mating and the study of macronuclear development in Euplotes crassus. I. Cell Biol. 101: 79-84.

Sanger, F., S. Nicklen, and A. Coulson. 1977. DNA sequencing with chain-terminating inhibitors. Proc. Natl. Acad. Sci. 74: 5463-5467.

Shippen-Lentz, D. and E.H. Blackburn. 1989. Telomere terminal transferase activity from Euplotes adds large numbers of TTTTGGGG repeats onto telomeric primers. Mol. Cell. Biol., in press.

Steinbruck, G. 1983. Overamplification of genes in macronuclei of hypotrichous ciliates. Chromosoma 88: 156-163.

- 1986. Molecular reorganization during nuclear differentiation in ciliates. In Results and problems in cell differentiation, Vol. 13 Germ line-soma differentiation. (ed. W. Hennig), pp. 105-174. Springer-Verlag, Berlin.

Swanton, M.T., J.M. Heumann, and D.M. Prescott. 1980. Genesize DNA molecules of the macronuclei in three species of hypotrichs: Size distribution and absence of nicks. Chromosoma 77: 217-227.

Tondravi, M.M. and M.-C. Yao. 1986. Transformation of Tetrahymena thermophila by microinjection of ribosomal RNA genes. Proc. Natl. Acad. Sci. 83: 4369-4373.

Tu, C.-P.D. and S.N. Cohen. 1980. $3^{\prime}$-end labeling of DNA with $(\alpha-32 \mathrm{P})$ cordycepin-5'-triphosphate. Gene 10: 177-183.

Yao, M.-C., K. Zheng, and C.-H. Yao. 1987. A conserved nucleotide sequence at the sites of developmentally regulated chromosome breakage in Tetrahymena. Cell 48: 779-788.

Zahler, A.M. and D.M. Prescott. 1988. Telomere terminal transferase activity in the hypotrichous ciliate Oxytricha nova and a model for the replication of the ends of linear DNA molecules. Nucleic Acids Res. 16: 6953-6972. 


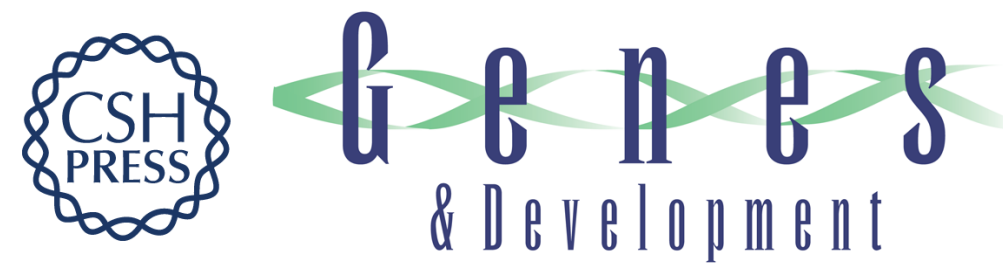

\section{Characterization of chromosome fragmentation in two protozoans and identification of a candidate fragmentation sequence in Euplotes crassus.}

S E Baird and L A Klobutcher

Genes Dev. 1989, 3:

Access the most recent version at doi:10.1101/gad.3.5.585

References This article cites 39 articles, 14 of which can be accessed free at:

http://genesdev.cshlp.org/content/3/5/585.full.html\#ref-list-1

License

Email Alerting Receive free email alerts when new articles cite this article - sign up in the box at the top Service right corner of the article or click here.

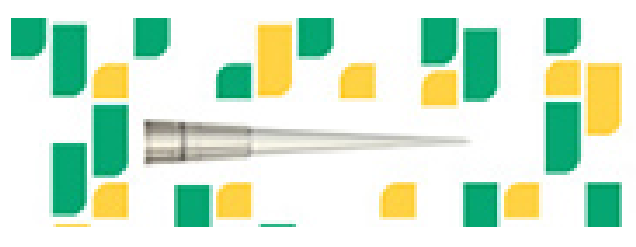

Focused on your science. 